\title{
MARKETING THROUGH INSTAGRAM INFLUENCERS: IMPACT OF NUMBER OF FOLLOWERS AND PRODUCT DIVERGENCE ON BRAND ATTITUDE
}

Marijke De Veirman, Ghent University, Belgium

Veroline Cauberghe, Ghent University, Belgium

Liselot Hudders, Ghent University, Belgium

Marijke De Veirman, Ghent University

Ghent University, Faculty of Political and Social Sciences

Korte Meer 11, 9000 Ghent

Email: marijke.deveirman@ugent.be

Tel. nr. 3292649722 


\title{
MARKETING THROUGH INSTAGRAM INFLUENCERS: IMPACT OF NUMBER OF FOLLOWERS AND PRODUCT DIVERGENCE ON BRAND ATTITUDE
}

\begin{abstract}
Findings from two experiments show that Instagram influencers with high numbers of followers are considered more likeable, mostly because they are considered more popular. Important, only in limited cases, perceptions of popularity due to the influencer's number of followers, lead to perceptions of opinion leadership. Furthermore, one should also take into account number of followees, as very low numbers of followees might negatively impact popular influencers' likeability. Also, cooperating with influencers with high numbers of followers might not be the best marketing choice for promoting divergent products, as this lowers the brand's perceived uniqueness and consequently brand attitudes.
\end{abstract}

\section{INTRODUCTION}

Recently, brands discovered the far-reaching impact and viral growth potential of approaching influencers - people who built a large network of followers, and are regarded as trusted tastemakers in one or several niches - to promote their products. A major challenge for brands that aim to apply this type of WOM-marketing, is to identify and select influencers whom may have a strong impact on their target audience and convince them to incorporate their products in their posts, this way diffusing them (Wong, 2014). Today, number of followers, which reflects network size and serves as an indication for popularity, is frequently used to identify these influential nodes. Accordingly, higher numbers of followers may result in larger reach of the (commercial) message and may thus leverage the power of WOM at scale (Talavera, 2015). However, to our knowledge, no research yet investigated how people perceive and evaluate these numbers. Moreover, the reach of the message through an influencer should not be the only criterion for successful persuasive communication. To increase the message's impact one should search for the most likeable, trustable influencer which has a high value as opinion leader. Hence, in two studies, we aim to provide more insights in the characteristics that make an influencer efficient above and beyond their potential reach. Study I explores which Instagram influencer is the best marketing choice in terms of number of followers and followees. First, it is investigated whether numbers of followers merely affect perceptions of popularity, or whether it might also cause people to ascribe opinion leadership to the influencer. Next, the relationship between number of followers and likeability through perceived popularity and sequentially ascribed opinion leadership is examined. In addition, the moderating impact of number of followees on the proposed relationship between number of followers and likeability is considered. Study II further examines the moderating role of number of followers on the advertising effectiveness of influencers' posts. In particular, effectiveness in terms of attitude towards the brand (Ab) of posts containing products with common and divergent designs will be investigated.

\section{THEORETICAL BACKGROUND AND HYPOTHESES DEVELOPMENT}

\section{The Impact of Number of Followers on Influencer Likeability}

A high number of followers implies that many people are interested in a certain account, as they subscribed to its updates. People rely on this cue to assess one's popularity and popular 
users are perceived more attractive, extravert, trustworthy, approachable and possessing other socially desirable characteristics (Jin and Phua, 2014; Utz, 2010; Graham, 2014). It thus seems plausible that an influencer with a high number of followers will be perceived as generally more likeable because he/she is perceived as more popular. However, likeability should preferably result from the fact that consumers see the influencer as a valuable source of information - an opinion leader - rather than merely from popularity. As number of followers indicates audience size and influencers disseminate their ideas among them, having more followers accelerates the diffusion of information (Yoganarasimhan, 2012). A high number of followers could thus be advantageous to the exertion of opinion leadership as ideas are spread more widely and rapidly and consequently, interpersonal influence is enhanced (Cha, Haddadi, Benevenuto, and Gummadi 2010). In line with this reasoning, number Twitter followers was found to contribute to one's opinion leader status (Feng, 2016) and opinion leaders have the intention to build large groups of followers (Hwang, 2015). This leads to the proposition that an influencer who is perceived as popular, elicits perceptions of opinion leadership. Contrary to these findings however, it was found that the number of Twitter followers does not predict actual influence. As such, Cha et al. (2010) found that the number of followers represents a user's popularity, however, this does not imply that this user is also retweeted or mentioned. Similar, Romero Galuba, Asur and Huberman (2010) found that number of followers is an indication for popularity, however this does not mean that they will also engage with the posted content by retweeting it, etc. It is thus unsure whether people who perceives an influencer as popular, also consider him/her as an opinion leader. Most likely, the indirect effect of number of followers on likeability will be partly explained by higher perceptions of popularity, and partly by a sequential mediation of perceptions of popularity and opinion leadership. Thus, we propose the following hypothesis:

H1. The indirect effect of number of followers on likeability will partly be explained by perceived popularity and partly by perceived popularity and ascribed opinion leadership.

\section{The Moderating Impact of Number of Followees on the Relation between Number of Followers and Influencer Likeability}

Besides number of followers, number of followees and the combination of both may affect one's perceptions about the influencer. In popular literature, some "rules" about who to follow and the ideal "followers/followee ratio", mostly concerning Twitter, exist. For example, a rule of thumb is that you should especially follow people with a positive ratio, people who have more followers than followees. It is likely that Instagram users with high numbers of followers who follow few people themselves are perceived as true influencers as their follower base doesn't merely consists of people who followed him/her back after (s)he started following them. Thus, highly positive ratios could be an indication of true opinion leadership. On the other hand, it is said that users with a lot of followers in combination with only a few followees, are no "true" Twitter users (Siegler, 2009) or it indicate that the followers are artificially collected or "fake" (Cresci, Di Pietro, Petrocchi, Spognardi and Tesconi, 2015). In contrast, a user with many followees has more opportunities to learn about different topics and opinions, and thus more ability to look beyond their own social environment, which might be beneficial in terms of opinion leadership (Williams 2006). Today, no study has investigated whether number of followees is an important trait for consumers in the assessment of an influencer. Therefore, we propose the following research question:

RQ1. Does the number of followees have an influence on the relationship between the influencer's number of followers and its likeability? 


\section{The Moderating Impact of Product Divergence on the Relation between Number of Followers and Influencer Effectiveness}

As number of followers represents the audience with whom influencers share their ideas, a higher number of followers might elicit greater brand effects. Jin et al. (2014) recently illustrated this idea and found that positive tweets from celebrities with a high number of followers result in higher product-involvement and buying intentions than tweets from less popular celebrities. However, we expect that the impact of the number of followers might be different according to the type of product. Previous research pointed to the influence of others (i.e. social influence) on consumption behavior and identified two opposite social needs that may explain consumers' preferences for (non-)divergent products, the need for uniqueness and the need for conformity, that might influence consumers' choices. In practice, sometimes consumers may be very attracted to unique products that are not obvious to obtain, but at other times, they might want to buy what others bought (Steinhart, Kamins, Mazursky and Noy, 2014). Consumers evaluate products to decide whether they respond to their needs. However, they rarely have complete information, which makes evaluation hard. Therefore, they often make inferences to fill in these gaps. These inferences have been referred to as naïve theories and serve as common-sense explanations to evaluate and make inferences regarding marketing communication, products and brands (Deval, Mantel, Kardes and Posavac, 2013). Two naïve theories may be linked to the need for uniqueness and conformity: the naive theory of exclusivity or the belief that exclusive products are desirable (Berger and Heath, 2007), and the naive theory of popularity or the belief that popular products are desirable, similar to "bandwagon" effects (Henshel and Johnston, 1987; Deval et al., 2013). Following the naïve theory of exclusivity, we expect consumers to have a better attitude towards brands with divergent product designs compared to brands with standard designs because they are perceived as more unique. However, if the product is posted by an influencer with a high number of followers, this might trigger the naïve theory of popularity and thoughts that the product is rather common instead of unique. When such an influencer promotes a divergent product, product uniqueness might diminish due to the idea that many others might be interested in the product as well (Machleit, Eroglue and Mantel, 2000). Hence, we expect the positive relationship between product diversity and attitude towards the brand through perceived uniqueness to be weakened when the product is posted by an influencer with a very high number of followers. We hypothesize:

H2. The positive effect of product divergence on brand attitude through perceived divergence will be weaker if the brand is promoted by an influencer with a high number of followers compared to when it is promoted by an influencer with a moderate number of followers.

\section{STUDY 1: ASSESSING THE LIKEABILITY OF INSTAGRAM INFLUENCERS}

\section{Method}

The experiment used a 2 (number of followers: moderate vs. high) by 2 (number of followees: low vs. high) between-subjects experimental design. An Instagram account for a fictitious influencer was created (a male and female version was created and linked to respondents' gender). The number of followers and followees were manipulated based on actual influencers' Instagram pages. In the moderate number of followers condition, the influencer was given 2100 followers, in the high amount of followers condition, this number was increased to $21.200(21.2 \mathrm{k})$. In the low number of followees condition, the influencer followed 32 people, in the high number of followers condition the influencer followed 32.200 
(32.2k) people. To check manipulations, participants were asked if they found the influencer had a very small $(=1)$ versus very large $(=7)$ number of followers/followees and if they thought the influencer's number of followers/followees was smaller $(=1)$ versus larger $(=7)$ than the average influencer's numbers. Credibility was measured using Ohanian's $(1990, \alpha=$ .90) 14-item scale. Popularity was measured with one item, asking participants to rate the popularity of the influencer. Opinion leadership was measured by an adapted version of the four-item scale of Flynn, Goldsmith and Eastman $(1996, \alpha=.92)$. Influencer likeability was measured using 3 items from Dimofte, Forehand and Deshpandé $(2004, \alpha=.85)$. All scales were measured using 5-point Likert scales. 117 Instagram users that were recruited via MTurk (74 females, $\mathrm{M}_{\text {Age }}=29.54$ years, $\mathrm{SD}_{\text {Age }}=6.55$ ) took part in the study.

\section{Results}

First, manipulation checks revealed that participants perceived number of followers to be lower $(\mathrm{M}=4.93, \mathrm{SD}=1.10)$ in the moderate followers condition than in the high followers condition $(\mathrm{M}=5.86, \mathrm{SD}=1.08, \mathrm{t}(115)=-4.59, \mathrm{p}<.001)$. Also, participants perceived the influencer's number of followees to be lower $(\mathrm{M}=2.26, \mathrm{SD}=1.75)$ in the low followees than in the high followees condition $(\mathrm{M}=6.11, \mathrm{SD}=1.32, \mathrm{t}(97.52)=-13.25, \mathrm{p}<.001)$. Next, a sequential mediation analysis (Process Macro, Model 6, see figure 1) showed a positive effect of number of followers on perceived popularity. It was found that perceived popularity has a marginally significant positive effect on perceived opinion leadership, which consequently has a positive effect on likeability. Bootstrapping showed an indirect effect for popularity (ab $=.15, \mathrm{SE}=.07 ; 95 \% \mathrm{CI}=[.032 ; .32])$, as predicted in $\mathrm{H} 1$, but not for opinion leadership $(\mathrm{ab}=$ $-.01, \mathrm{SE}=.03 ; 95 \% \mathrm{CI}=[.04 ; .08])$. Important, the serial indirect effect was significant, however small $(\mathrm{ab}=.01, \mathrm{SE}=.01 ; 95 \% \mathrm{CI}=[.00 ; .05])$. Furthermore, a moderated mediation analysis (Process Macro, model 8) with number of followers as independent variable, number of followees as moderator, opinion leadership as mediator, likeability as dependent variable and perceived popularity as covariate, showed no significant moderated mediation, $a b=.05$, $\mathrm{SE}=.06,95 \% \mathrm{CI}=[-.02 ; .23]$. However, a direct conditional effect of number of followers on likeability was found. This effect suggests a negative direct effect of number of followees on likeability when the number of followers is low $\left(c^{\prime}=-.38, \mathrm{SE}=.17,95 \% \mathrm{CI}\right.$ : $=[-.72$; $.04])$, while this effect is no longer significant when the number of followers is high $\left(c^{\prime}=.08\right.$, $\mathrm{SE}=.16,95 \% \mathrm{CI}:=[-.24 ; .39])$.

\section{STUDY 2: ASSESSING THE BRAND EFFECTS OF INSTAGRAM INFLUENCERS}

\section{Method}

The study used a 2 (number of followers: moderate vs. high) by 2 (product divergence: low vs. high) between-subjects experimental design. An Instagram account with a high and low number of followers was created. The number of followees $(\mathrm{N}=320)$ and number of posts $(\mathrm{N}$ = 366), was kept constant. After viewing the profile, participants read that the influencer recently posted a picture on Instagram and participants were instructed to view the post carefully. Divergence was manipulated by manipulating product design (Warren and Campbell, 2014). To check manipulations, participants were asked if they found the influencer had a very small $(=1)$ versus very large $(=7)$ amount of followers Product divergence was measured by Warren et al.'s (2014) three-items scale $(\alpha=.88)$. Participants had to evaluate whether the design "is different from the norm", "is unique" and "shows 
independence" $(\alpha=.88)$. Ab was measured with five items (Spears and Singh, 2004, $\alpha=.93$ ). Uniqueness of the brand was measured with 4 items of the uniqueness dimension of Netemeyer, Krishnan, Pullig, Wang, Yagci, Dean, Ricks and Wirth's $(2004, \alpha=.94) 10$-item Brand Equity scale. All scales were measured with 5 point Likert scales. 118 female participants recruited from MTurk completed the study (Mage $=26.92$ years, $\mathrm{SD}_{\text {Age }}=4.24$ ).

\section{Results}

First, manipulation checks revealed that participants perceived the influencer's amount of followers to be lower $(\mathrm{M}=5.56, \mathrm{SD}=1.08)$ in the moderate follower condition than in the high follower condition $(\mathrm{M}=6.02, \mathrm{SD}=1.17, \mathrm{t}(116)=-2.19, \mathrm{p}=.030)$. The low divergent product $(\mathrm{M}=2.91, \mathrm{SD}=.97)$ was evaluated significantly lower in divergence than the high divergent product $(\mathrm{M}=4.25, \mathrm{SD}=.60, \mathrm{t}(116)=-8.94, \mathrm{p}<.001)$. Next, a moderated mediation analysis (Process Macro, Model 7, see figure 2 and 3) with amount of followers as moderator of the effect of product divergence on $\mathrm{Ab}$ through perceived uniqueness of the brand, revealed the presence of moderated mediation $(\mathrm{ab}=-.50, \mathrm{SE}=.20,95 \% \mathrm{CI}:=[-.93$; .15]). When the number of followers was moderate, there was a significant positive effect of divergence on $\mathrm{Ab}$ through perceived uniqueness, $\mathrm{ab}=.80, \mathrm{SE}=.150,95 \% \mathrm{CI}:=[.53,1.12]$. When the number of followers was high, the positive effect of divergence on Ab through perceived uniqueness was weakened, $\mathrm{ab}=.29, \mathrm{SE}=.146,95 \% \mathrm{CI}:=[.01 ; .58]$. Our data suggest that divergence has a positive effect on perceived uniqueness, which, in turn, increases attitude towards the brand. However, this process is conditional on number of followers of the influencer: if the product is posted by an influencer with a moderate number of followers, this effect is stronger than if the product is posted by an influencer with a high number of followers, confirming hypothesis 2 .

\section{GENERAL DISCUSSION}

Comparing different number of followers on an Instagram influencer's likeability, study I found that having more followers increases likeability, for the most through higher perceptions of popularity and for a small part because these higher perceptions of popularity leads people to ascribe more opinion leadership to the influencer. A high number of followers may thus lead to higher perceptions of popularity, and subsequently higher likeability, but it does not mean that the influencer is automatically perceived as an opinion leader, as this is only true for a small part of our sample. Furthermore, a negative relationship between number of followers and likeability can arise when a popular influencer follows very few people him/herself. There was thus found evidence for the negative implications of "hugely positive ratio's" (Siegler, 2009). Important, when searching for an appropriate influencer, marketers must also consider the type of product they want to promote. In study II it was found that divergence has a positive effect on perceived uniqueness, which, in turn, increases attitude towards the brand, in line with the naïve theory of exclusivity (Berger et al. 2007). However, the effect of divergence on perceived uniqueness appeared to be stronger when the influencer's number of followers was moderate compared to high. As expected, a high number of followers triggered the idea that the product is not that unique after all, as many others are interested in it (Machleit et al., 2000). These findings are consistent with Hellofs and Jacobson's (1999) findings that if the market share of exclusive products grows, this may infer a loss of exclusivity for consumers. Therefore, the topics influencers post about and the audience they reach in terms of interests and activities, rather than the size of their audience might be more important to take into account. 


\section{REFERENCES}

Berger, J., Heath, C. (2007). Where consumers diverge from others: Identity signaling and product domains. Journal of Consumer Research, 34, 121-134.

Campbell, C., Pitt, L. F., Parent, M., Berthan, P. R. (2011). Understanding consumer conversations around ads in a web 2.0 world. Journal of Advertising, 40(1), 87-102.

Cha, M., Haddadi, H., Benevenuto, F., Gummadi, K. (2010). Measuring user influence in Twitter: The million follower fallacy. Proceedings of the Fourth International AAAI Conference on Weblogs and Social Media, Washington D.C., USA.

Chen, Y., Fay, S., Wang, Q. (2011). The Role Of Marketing In Social Media: How Online Consumer Reviews Evolve, Journal of Interactive Marketing, 25(2), 85-94.

Cresci, S., Di Pietro, R., Petrocchi, M., Spognardi, A., Tesconi, M. (2015). Fame for sale: efficient detection of fake Twitter followers, Decision Support Systems, 80, 56-71.

Deval, H., Mantel, S. P., Kardes, F. R., Posavac, S. S. (2013). How naive theories drive opposing inferences from the same information. Journal of Consumer Research, 39, $1185-1201$.

Dimofte, C. V., Forehand, M. R., Deshpandé, R. (2004). Ad schema incongruity as elicitor of ethnic self-awareness and differential advertising response. Journal of Advertising, 32(4), 7-17.

Feng, Y. (2016). Are you connected? Evaluating information cascades in online discussion about the \#RaceTogether campaign. Computers in Human Behavior, 54@, 43-53.

Flynn, L. R., Goldsmith, R. E., Eastman, J. K. (1996). Opinion leaders and opinion seekers: Two new measurement scales. Journal of the Academy of Marketing Science, 24(2), 137 147.

Graham, G. S. (2014). More Than Friends: Popularity on Facebook and its Role in Impression Formation. Journal of Computer-Mediated Communication, 19(3), 358-372.

Hellofs, L., Jacobson, R. (1999). Market share and customers' perceptions of quality: When can firms grow their way to higher versus lower quality. Journal of Marketing, 63, 16-25.

Hwang, Y. (2015). Does opinion leadership increase the followers on Twitter. International Journal of Social Science and Humanity, 5(3), 258-264.

Jin, S. A., Phua J. (2014). Following Celebrities' Tweets About Brands: The Impact of Twitter-Based Electronic Word-of-Mouth on Consumers' Source Credibility Perception, Buying Intention, and Social Identification With Celebrities., Journal of Advertising, 43(2), 181-195.

Lynn, M. (1992). The psychology of unavailability: Explaining scarcity and cost effects on value. Basic and Applied Social Psychology, 13, 3-7.

Machleit, K. A., Eroglue, S. A., Mantel, S. P. (2000). Perceived retail crowding and shopping satisfaction: What modifies this relationship? Journal of Consumer Psychology, 9 29-42.

Netemeyer, R. G., Krishnan, B., Pullig, C., Wang, G., Yagci, M., Dean, D., Ricks, J., Wirth, F. (2004). Developing and validating measures of facets of customer-based brand equity. Journal of Business Research, 57, 209-224. 
Ohanian, R. (1990). Construction and validation of a scale to measure celebrity endorsers' perceived expertise, trustworthiness, and attractiveness. Journal of Advertising, 19(3), 3952.

Posavac, S. S., Herzenstein, M., Karde, F. R., Sundaram, S. (2010). Profits and halos: The role of firm profitability information in consumer inference. Journal of Consumer Psychology, 20(3), 327-337.

Romero, D. M., Galuba, W., Asur, S., Huberman, B. A. (2010). Influence and passivity in social media. Proceedings of the European Conference on Machine Learning and Knowledge Discovery in Databases, Athens, Greece.

Siegler, M.G. (2009). Twitter's golden ratio (That no one likes to talk about). Retrieved February 26, 2016 from http://techcrunch.com/2009/08/26/twitters-golden-ratio-that-noone-likes-to-talk-about/

Spears, N0, Singh, S. N. (2004). Measuring attitude toward the brand and purchase intentions. Journal of Current Issues \& Research in Advertising, 26(2), 53-66.

Steinhart, Y., Kamins, M., Mazursky, D., Noy, A. (2014). Effects of product type and contextual cues on eliciting naive theories of popularity and exclusivity. Journal of Consumer Psychology, 24(4), 472-483.

Talavera, M. (2014). 10 reasons why influencer marketing is the next big thing. Retrieved March 10, 2016 from http://www.adweek.com/socialtimes/10-reasons-why-influencermarketing-is-the-next-big-thing/623407

Utz, S. (2010). Show me your friends and I will tell you what type of person you are: How one's profile, number of friends, and type of friends influence impression formation on social network sites. Journal of Computer-Mediated Communication, 15(2), 314-335.

Warren, C., Campbell, M. C. (2014). What makes things cool? How autonomy influences perceived coolness. Journal of Consumer Research, 41, 543-563.

Williams, D. (2006). On and off the 'net: Scales for social capital in an online era. Journal of Computer-mediated Communication, 11, 593-628

Wong, K. (2014). The explosive growth of influencer marketing and what it means for you. $\begin{array}{llll}\text { Retrieved February } & 2616 \text { from }\end{array}$ http://www.forbes.com/sites/kylewong/2014/09/10/theexplosive-growth-of-influencer-marketing-and-what-it-means-for-you/\#660f82d4595f

Yoganarasimhan, H. (2012). Impact of Social Network Structure on Content Propagation - A Study using YouTube Data. Quantitative Marketing and Economics, 10(1), 111-150. 


\section{LIST OF FIGURES}

Figure 1: Illustration of the Effect of Number of Followers on Likeability through Perceived Popularity and Ascribed Opinion Leadership

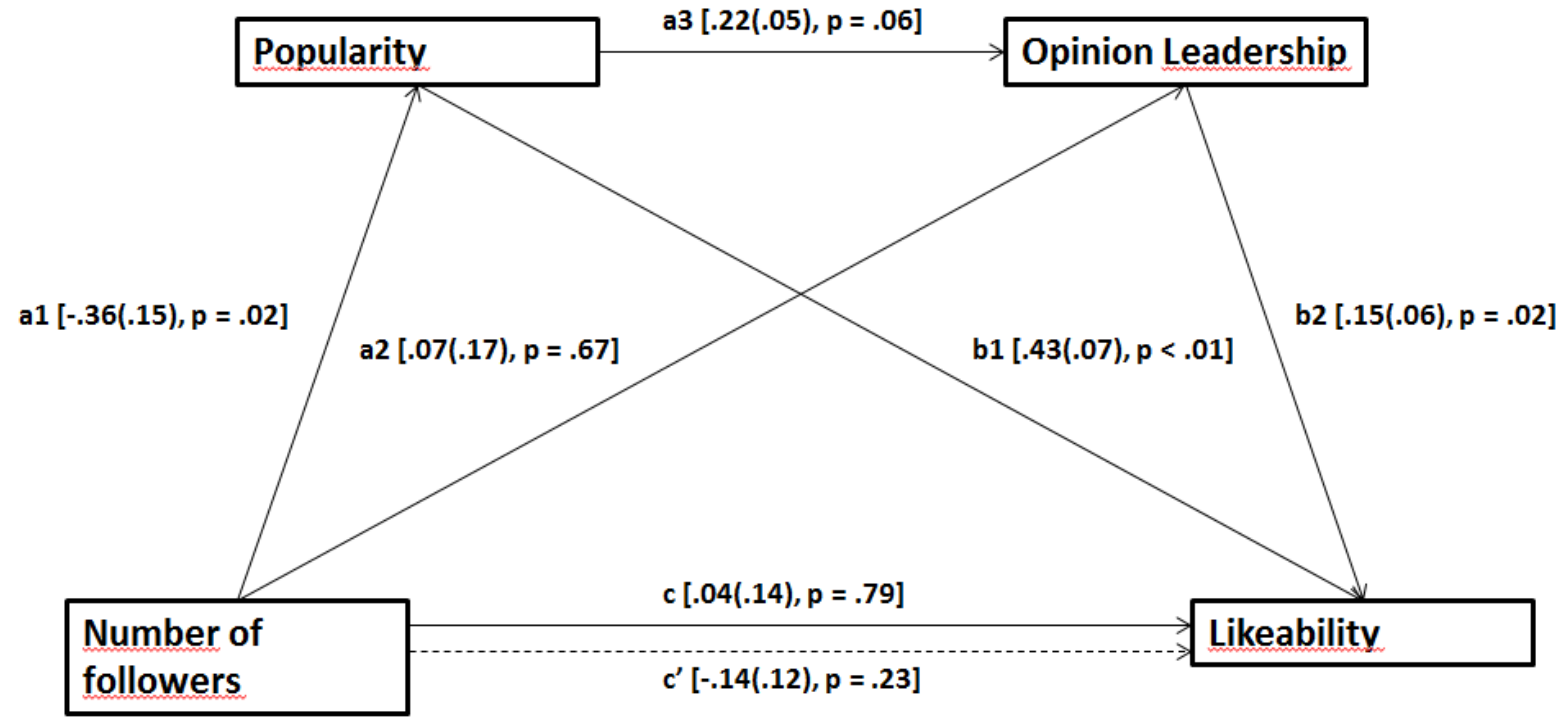


Figure 2: Illustration of the Conditional Direct Effect of Number of Followers on Likeability when the Number of Followees is low vs. high
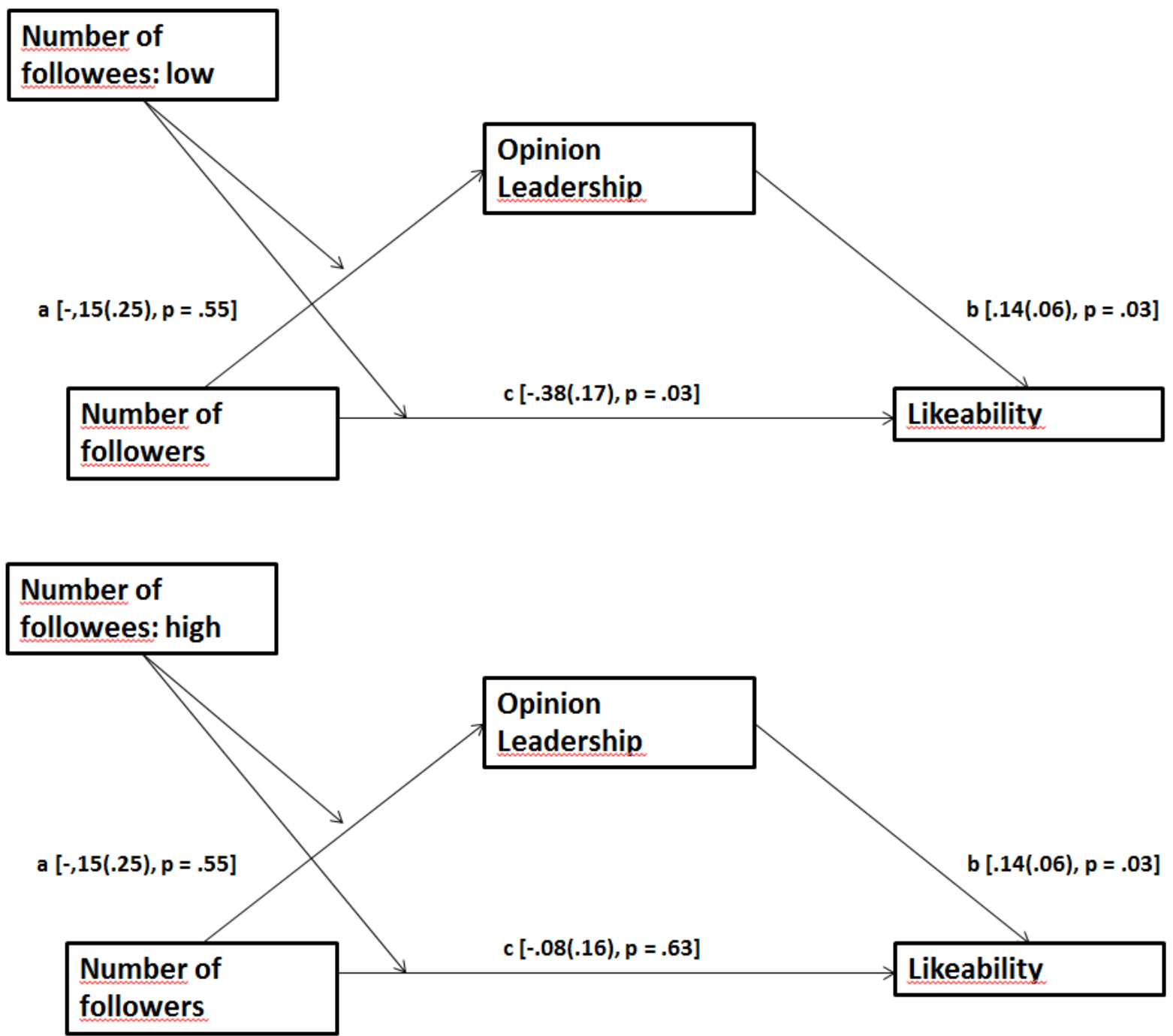
Figure 3: Effect of Divergence on Perceived Uniqueness, Depending on the Influencer's Number of Followers

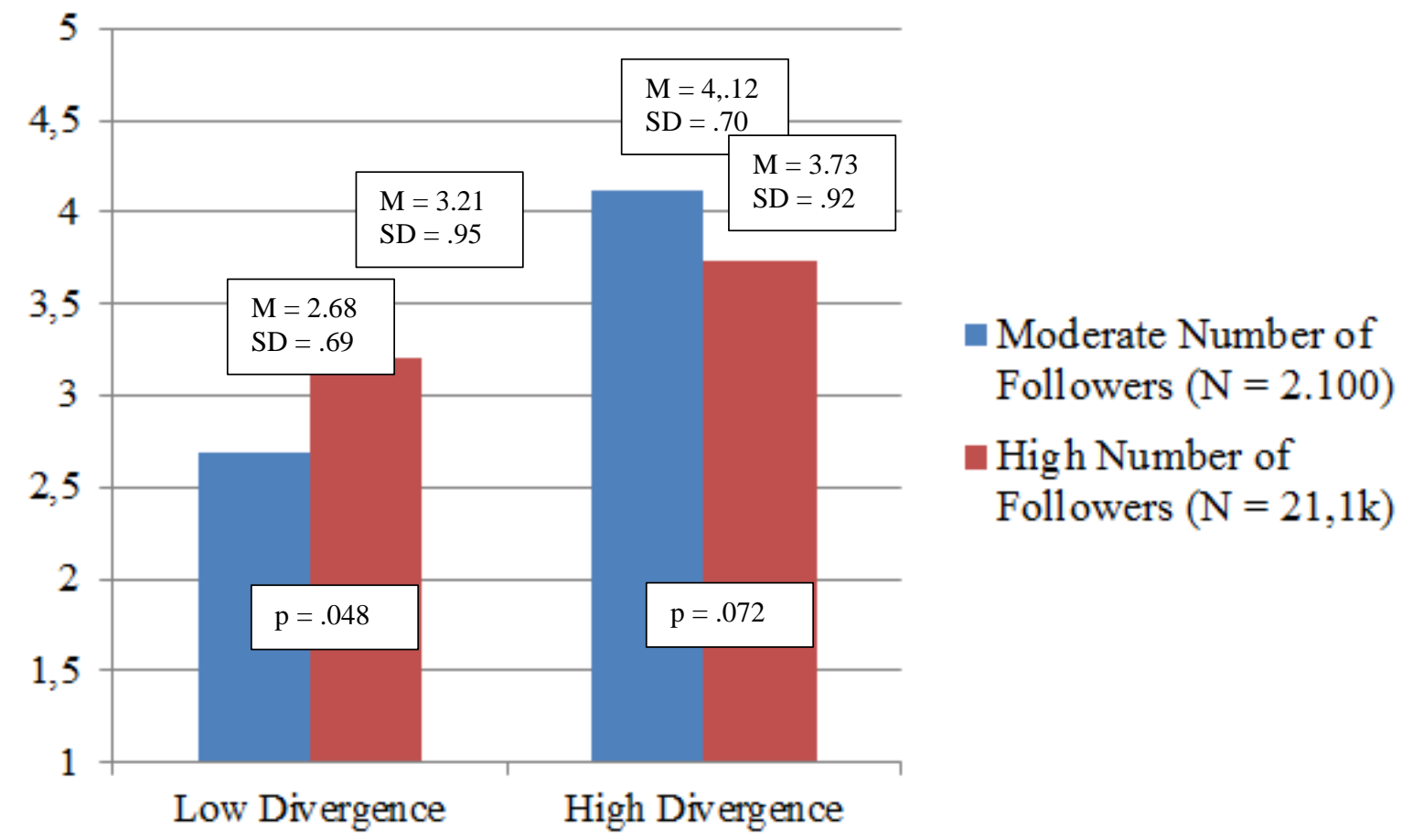

Figure 4: Tested Moderated Mediation Model: Effect of Divergence on Ab via Uniqueness, Moderated by Number of Followers

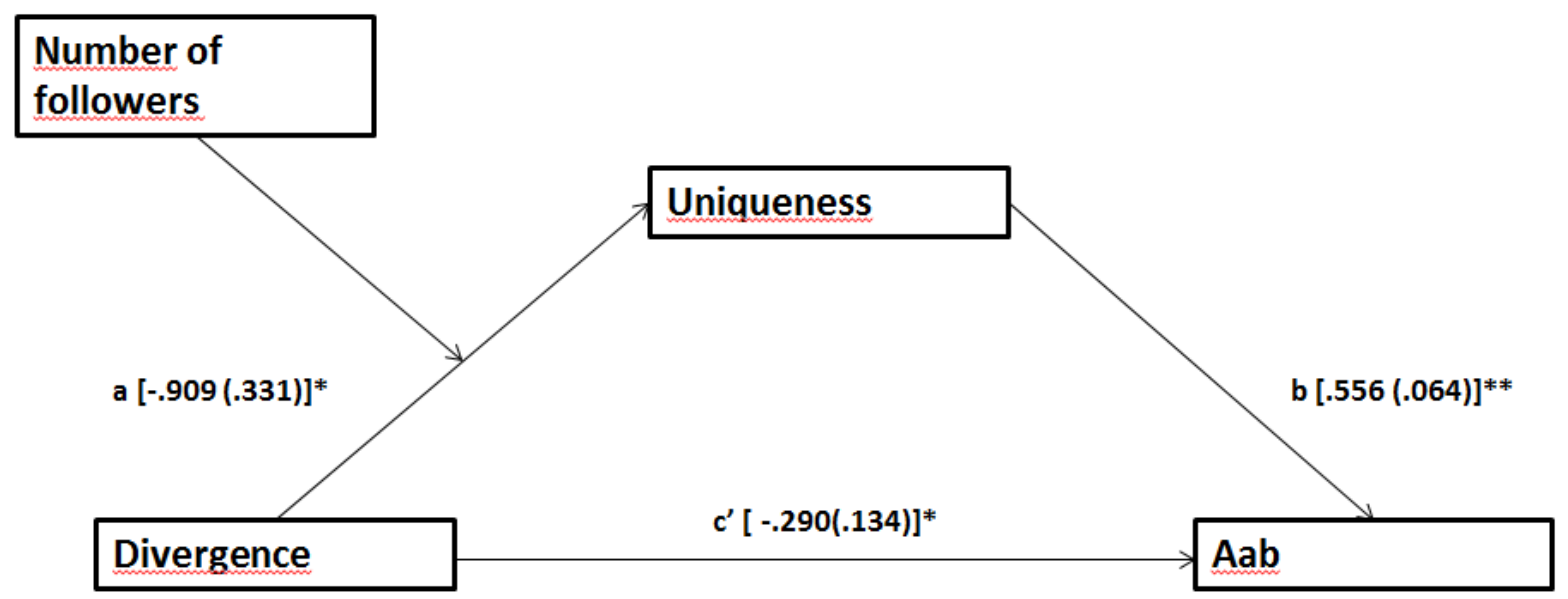

$+\mathrm{p}<.10, * \mathrm{p}<.05, * * \mathrm{p}<.001$ 
APPENDICES

Appendix A: Manipulation Stimuli Study I Female Participants
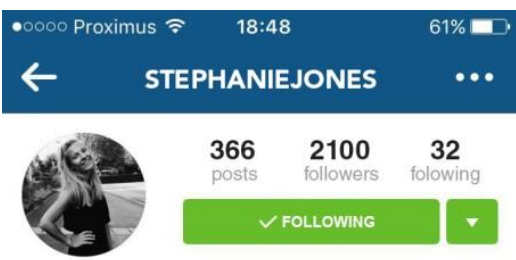

Stephanie Jones

Stephanie Jones I 24 y/o I My life in a nutshell | | Fashion I Travel I Health I Food |
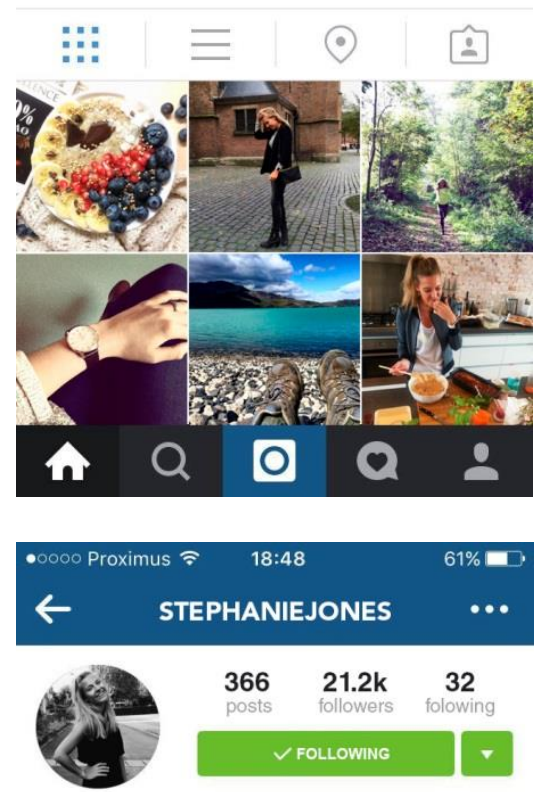

Stephanie Jones

Stephanie Jones I 24 y/o I My life in a nutshell |

| Fashion | Travel | Health | Food |

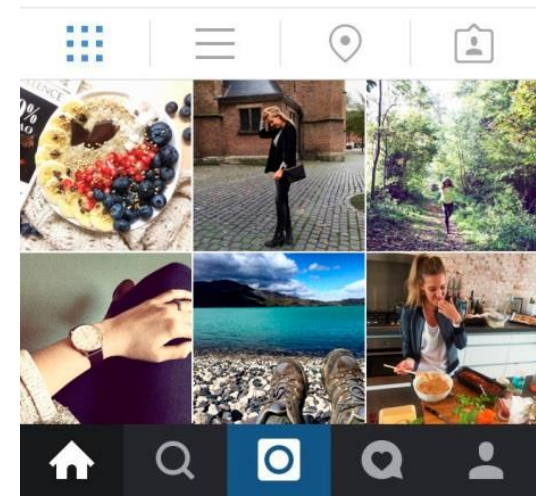

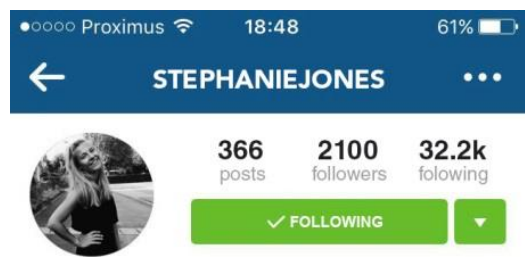

Stephanie Jones

Stephanie Jones I 24 y/o I My life in a nutshell I | Fashion I Travel I Health I Food I
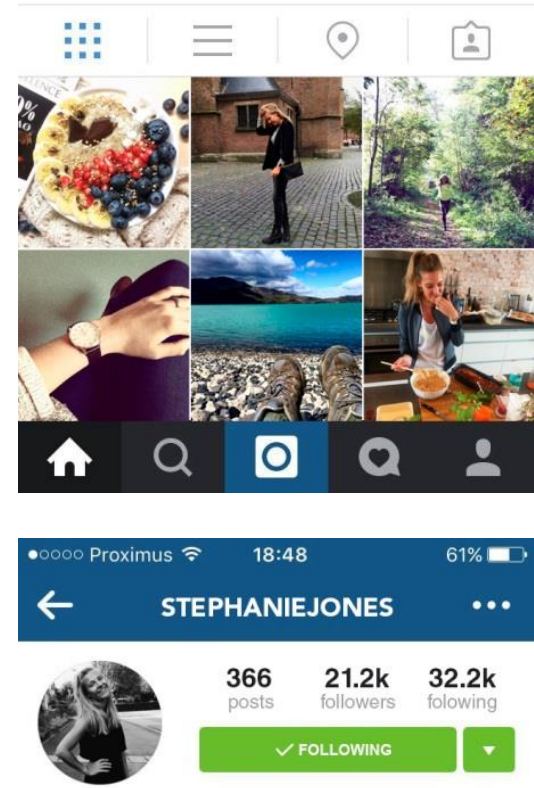

Stephanie Jones

Stephanie Jones I 24 y/o I My life in a nutshell |

| Fashion I Travel I Health I Food |

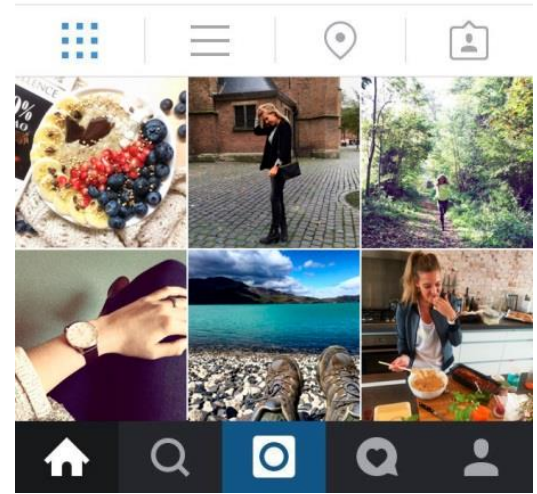


Appendix B: Manipulation Stimuli Study I Male Participants
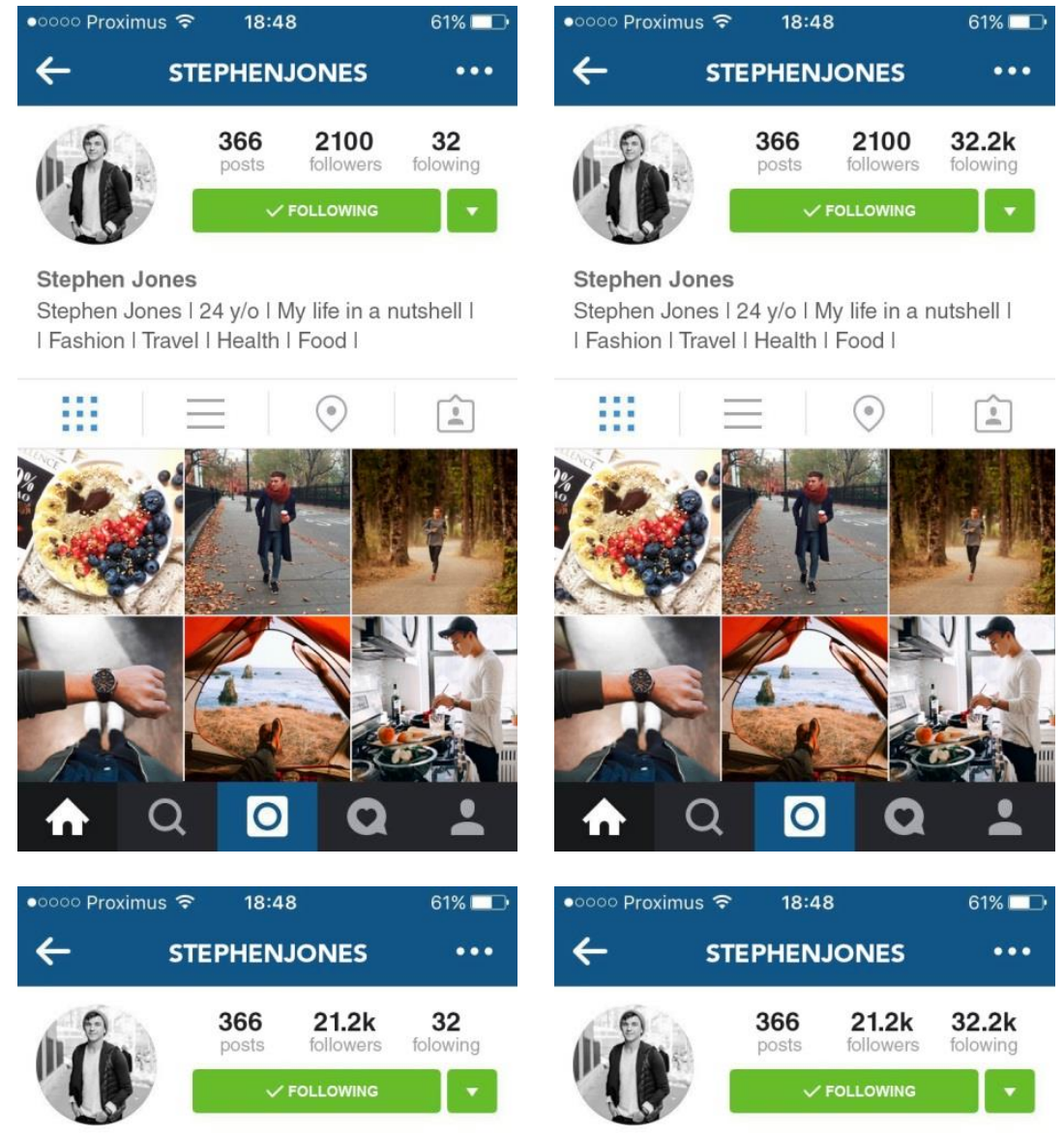

Stephen Jones

Stephen Jones I 24 y/o I My life in a nutshell I

| Fashion I Travel I Health I Food I

Stephen Jones

Stephen Jones I 24 y/o I My life in a nutshell | I Fashion I Travel I Health I Food I
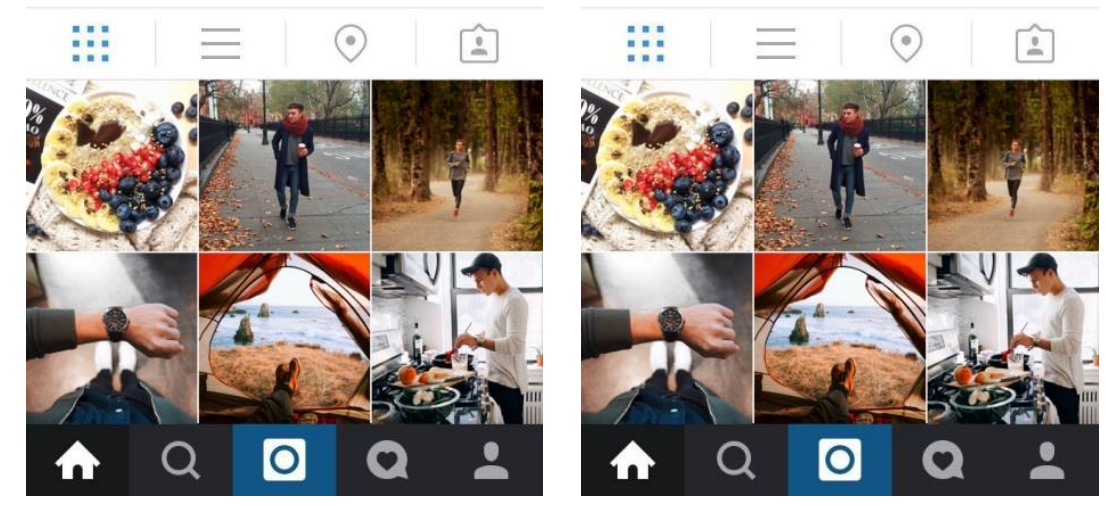
High Divergence

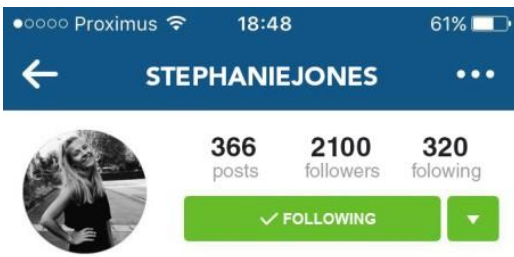

Stephanie Jones

Stephanie Jones I 24 y/o I My life in a nutshell I | Fashion I Travel | Health | Food |
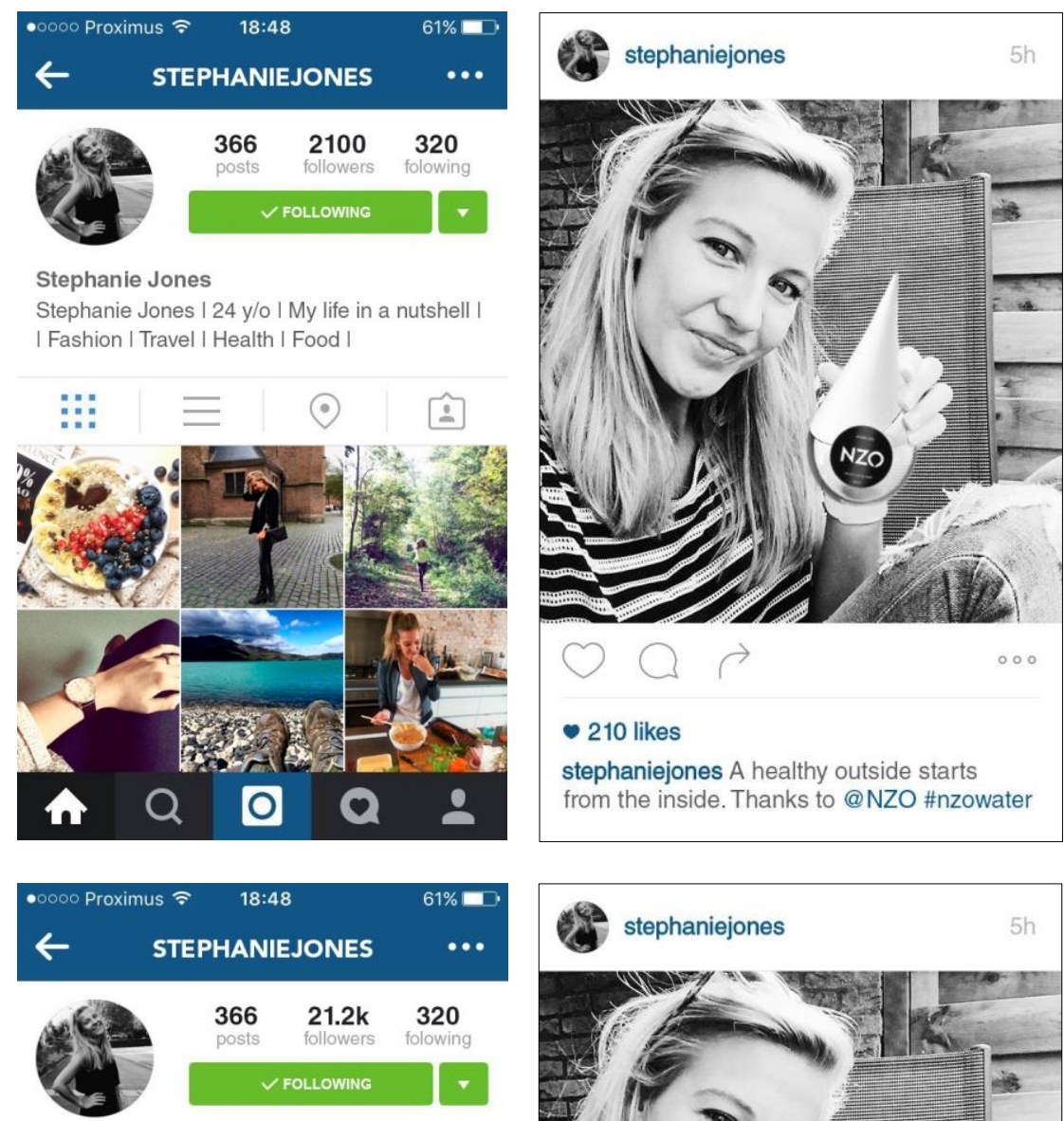

Stephanie Jones

Stephanie Jones I 24 y/o I My life in a nutshell I | Fashion I Travel | Health I Food |

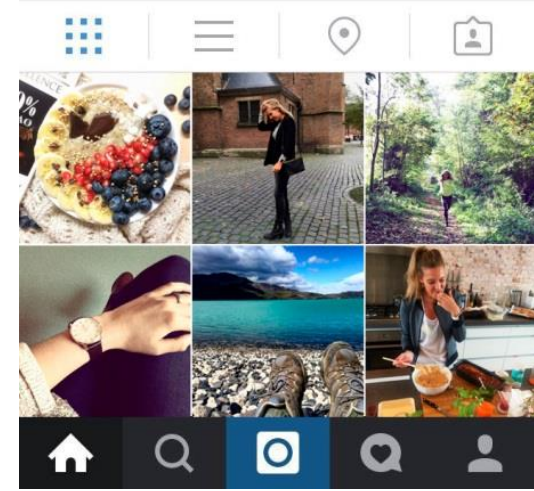

Low Divergence
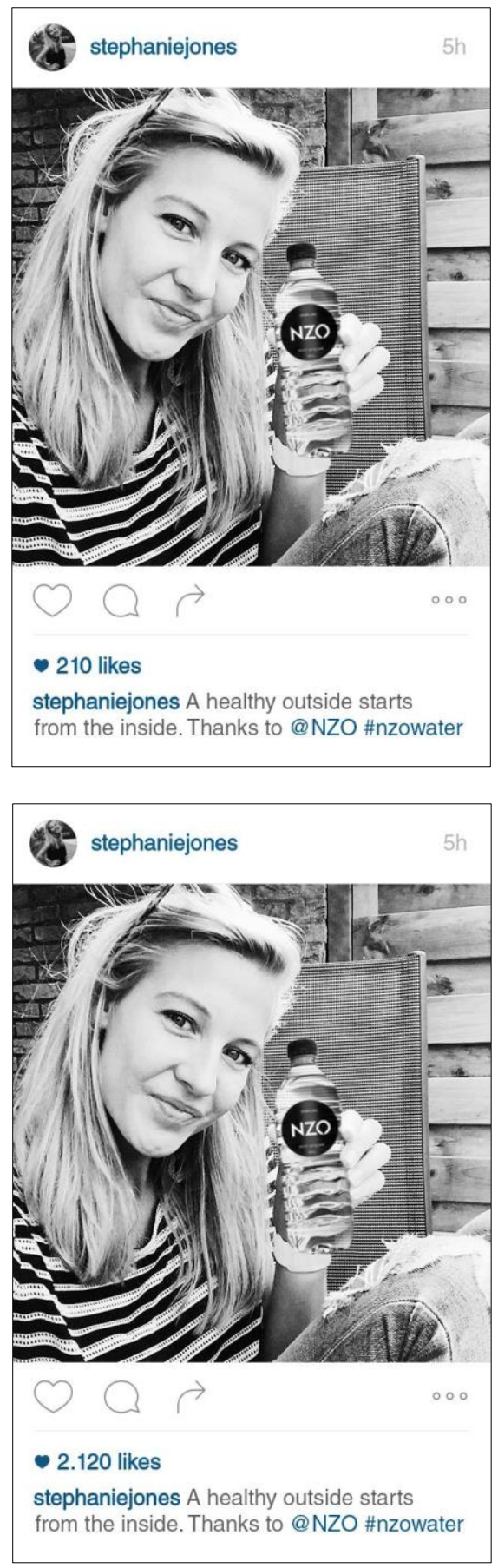